\title{
Rice Production Forecasting System in East Java Using Double Exponential Smoothing Method
}

\section{Sistem Peramalan Produksi Padi di Jawa Timur Menggunakan Metode Double Exponential Smoothing}

\author{
Siti Nurul Afiyah ${ }^{1}$, Fajar Kurniawan ${ }^{2}$, Nur Lailatul Aqromi ${ }^{3}$ \\ 1,2,3 Institut Teknologi dan Bisnis Asia Malang. Indonesia \\ \{fajar@asia.ac.id ${ }^{1}$,noeroel@asia.ac.id ${ }^{2}$, lyla@asia.ac.id ${ }^{3}$ \}
}

\begin{abstract}
Rice (Orza savita L.) is one of the most important carbohydrate-producing food plants in the world, besides wheat and corn. The need for rice continues to increase because the increase in the number of consumers is not balanced with sufficient production. According to BPS (2017), rice production in East Java Province in 2017 amounted to 13.06 million tons of Dry Milled Grain $(G K G)$. The aim of this research is to predict / forecast the yield of rice production in the next period in order to become the target of rice production in the next period. The raised problem is how to predict the rice production. From the data that has been obtained from 1993 to 2017 the data shows increasing gradually which is classified into trend data. Thus, the forecasting method that can be used is the double exponential smoothing method. In the calculation process, it is done by finding $S^{\prime}, S^{\prime}$ ', $a, b$ \& also the next period of forecasting sessions, using $0<x<1$. From the calculation of alpha $0.1-0.9$ obtained the smallest MAPE of 3.14 in alpha 0.5. The results of the forecast for the next period increased 13299827.49 tons with an accuracy of $96.86 \%$.
\end{abstract}

Keywords - Forecasting System; Double Exponential Smoothing; Rice Production

\begin{abstract}
Abstrak. Tanaman padi (Orza savita L.) adalah salah satu tanaman pangan penghasil karbohidrat yang terpenting di dunia, selain gandum dan jagung. Kebutuhan beras terus meningkat karena peningkatan jumlah konsumen tidak diimbangi dengan produksi yang cukup. Menurut BPS (2017), produksi padi di Provinsi Jawa Timur pada Tahun 2017 sebesar 13,06 juta ton Gabah Kering Giling (GKG). Tujuan dari penelitian ini adalah untuk memprediksi/ meramalkan hasil produksi padi periode berikutnya agar bisa menjadi target produksi padi pada periode berikutnya. Permasalahan yang diangkat adalah bagaimana meramalkan produksi padi. Dari data yang sudah didapatkan dari tahun 1993 sampai 2017 menjukkan data meningkat secara bertahap yang digolongkan menjadi data tren. Sehingga, metode peramalan yang bisa digunakan adalah metode double exponential smoothing. Dalam proses perhitungannya, dilakukan dengan mencari $S^{\prime}, S^{\prime}$, $, a, b$ \& juga sesi permalan periode berikutnya, dengan menggunakan $0<x<1$. Dari hasil perhitungan alfa 0,1-0,9 didapat MAPE terkecil sebesar 3,14 pada alfa 0,5. Hasil permalan produksi untuk periode berikutnya sebesar 13299827,49 ton dengan akurasi sebesar 96,86\%.
\end{abstract}

Kata Kunci - Sistem Peramalan; Double Exponential Smoothing; Produksi Padi

\section{Pendahuluan}

Tanaman padi (OrzasavitaL.) adalah salah satu tanaman pangan penghasil karbohidrat yang terpentingdi dunia, selain gandum dan jagung. Penduduk Indonesia, hampir 95\% mengkonsumsi beras sebagai bahan pangan pokok, sehingga pada setiap tahunnya permintaan akan kebutuhan beras semakin meningkat seiring dengan bertambahnya jumlah penduduk. Menurut Badan Pusat Statistik (2017) konsumsi beras di Indonesia tergolong tinggi yaitu sebesar $1,571 \mathrm{~kg} / \mathrm{kapita} / \mathrm{minggu}$ pada tahun 2017.

Sejalan dengan pertumbuhan penduduk dan pesatnya pembangunan diberbagai bidang, pemerintah di jawa timur menjalankan program varietas padi unggul yang merupakan program panen padi selama 4 kali dalam 1 tahun (masa panen 70 hari) yang telah menyumbang hasil panen sebesar 4,5 - 5,5 ton/ha. Dengan program ini pemerintah berhasil menyokong kebutuhan pangan di Jawa Timur meningkat sebesar 60\% [1].

Dengan adanya program verietas unggul padi, produksi panen padi meningkat secara bertaha. Menurut BPS (2017), produksi padi di Provinsi Jawa Timur pada Tahun 2017 sebesar 13,06 juta ton Gabah Kering Giling (GKG), tetapi konsumsi beras yang terlalu tinggi menyebabkan program diverifikasi pangan belum tercapai. Berdasarkan kondisi tersebut, dibutuhkan prediksi untuk mengetahui jumlah produksi padi pada periode selanjutnya. Berdasarkan data produksi padi pada tahun 1993-2017 didapatkan pola data trend naik. Maka dari itu metode peramalan yang cocok untuk pola data trend yaitu Metode Double Exponensial Smoothing [2].

Banyak peneliti yang sudah melakukan penelitian terkait dengan metode double exponential smoothing diantaranya Purwanto dan Afiyah yang meneliti tentang sistem peramalan produksi jagung provinsi Jawa Barat 
Procedia of Engineering and Life Science Vol. 1. No. 2 Juni 2021

Seminar Nasional \& Call Paper Fakultas Sains dan Teknologi (SENASAINS 2nd)

Universitas Muhammadiyah Sidoarjo

menggunakan metode double exponential smoothing [3], ada juga peneliti yang lain Afiyah dan Wijaya meneliti tentang system peramalan IHK mengunakan metode double exponential smoothing juga [4]. Serta masih banyak peneliti yang lain yang menggunakan metode double exponential smoothing [5][6][7][8][9].

\section{METODE}

\section{A. Analisa Data}

Dalam penelitian ini jenis data yang digunakan adalah time series (runtun waktu) dari tahun 1993 - 2017. Sumber data diperoleh dari Badan Pusat Statistika (BPS) dan data tersebut meliputi produksi padi di provinsi Jawa Timur. Data produksi padi akan diramal menggunakan data masa lalu yang akan dianalisa untuk memperkirakan suatu nilai pada masa yang akan datang. Berikut data produksi padi di provinsi Jawa Timur dapat dilihat pada Tabel 1:

Tabel 1. Data Produksi Pada Tahun 1993 Sampai Tahun 2017. (sumber : https://bps.go.id/)

\begin{tabular}{|c|c|c|}
\hline No & Tahun & Data \\
\hline 1 & 1993 & 8.627 .784 \\
\hline 2 & 1994 & 8.296 .348 \\
\hline 3 & 1995 & 8.572 .668 \\
\hline 4 & 1996 & 8.628 .766 \\
\hline 5 & 1997 & 8.533 .839 \\
\hline 6 & 1998 & 8.691 .519 \\
\hline 7 & 1999 & 8.956 .196 \\
\hline 8 & 2000 & 9.224 .353 \\
\hline 9 & 2001 & 8.672 .791 \\
\hline 10 & 2002 & 8.803 .878 \\
\hline 11 & 2003 & 8.914 .995 \\
\hline 12 & 2004 & 9.002 .025 \\
\hline 13 & 2005 & 9.007 .265 \\
\hline 14 & 2006 & 9.346 .947 \\
\hline 15 & 2007 & 9.402 .029 \\
\hline 16 & 2008 & 10.474 .773 \\
\hline 17 & 2009 & 11.259 .085 \\
\hline 18 & 2010 & 11.643 .773 \\
\hline 19 & 2011 & 10.567 .543 \\
\hline 20 & 2012 & 12.198 .707 \\
\hline 21 & 2013 & 12.049 .342 \\
\hline 22 & 2014 & 12.397 .049 \\
\hline 23 & 2015 & 13.154 .967 \\
\hline 24 & 2016 & 12.726 .463 \\
\hline 25 & 2017 & 13.060 .464 \\
\hline
\end{tabular}

Dari data pada Tabel 1 akan dijadikan plot grafik supaya dapat dianalisa, untuk mengetahui apakah pola data tersebut adalah plot data horizontal, trend, musiman, atau siklis. Plot data tren ada dua yaitu trend naik atau trend turun. Plot data produksi padi tahun 1993- 2017 digambarkan pada Gambar 1. 
Procedia of Engineering and Life Science Vol. 1. No. 2 Juni 2021

Seminar Nasional \& Call Paper Fakultas Sains dan Teknologi (SENASAINS $2^{\text {nd }}$ )

Universitas Muhammadiyah Sidoarjo

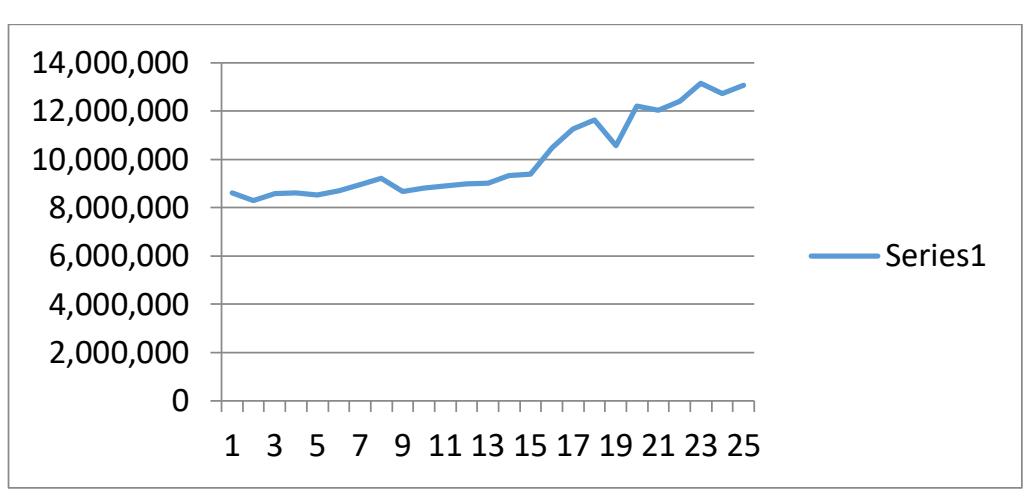

Gambar 1. Plot Data Produksi Pada Tahun 1993 Sampai Tahun 2017

Dari Gambar 1 terlihat bahwa plot Data Produksi Pada Tahun 1993 Sampai Tahun 2017 terus mengalami kenaikan. Maka dapat disimpulkan bahwa data produksi padi provinsi Jawa Timur membentuk pola data trend naik. Pola data trend bisa diramalkan menggunakan metode peramalan double exponential smoothing. Data yang akan diramalkan adalah data produksi padi di provinsi Jawa Timur tahun 2017-2021.

\subsection{Double Exponential Smoothing and MAPE (Mean Absolute Percentage Error)}

Dalam penelitian ini, dilakukan peramalan produksi padi mengunakan metode double exponential smoothing, dan berikut pada Gambar 2 merupakan flowchart dari metode tersebut [10].

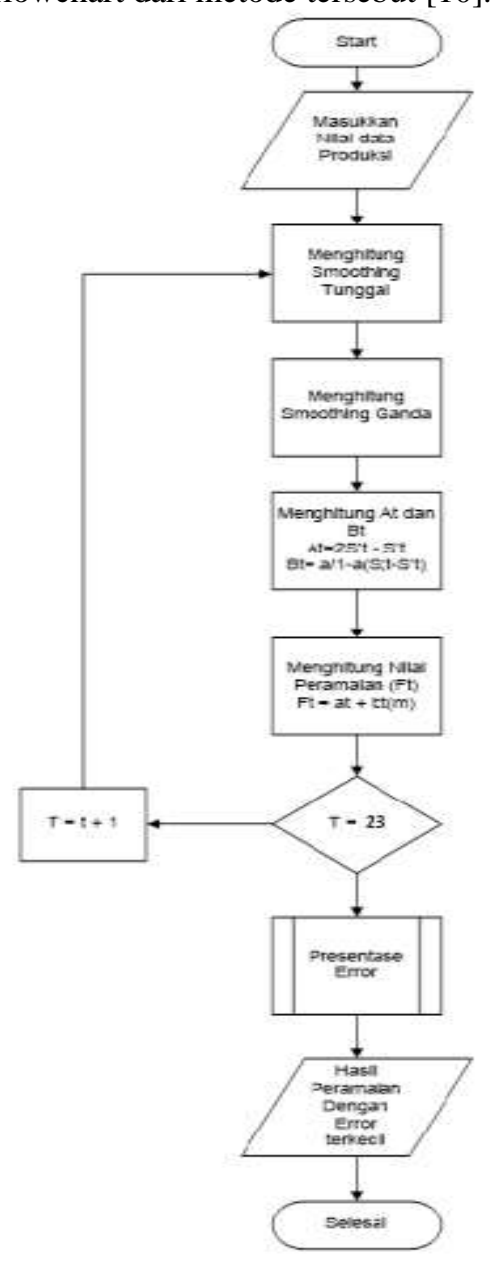

Gambar 2. Flowchart Metode Double Exponential Smoothing

Setelah perhitungan menggunakan metode double exponential smoothing, langkah selanjutnya adalah menghitung rata-rata kesalahan menggunakan rumus MAPE yang mana akan diambil kesimpulan peramalan dengan hasil nilai MAPE terkecil [11]. Dimana rumus dari MAPE adalah: 


$$
M A P E=\sum_{t=1}^{n} \frac{\left|\frac{X_{t}-F_{t}}{X_{t}}\right|}{n} \cdot 100
$$

Keterangan :

$X_{t}=$ data sebenarnya pada periode ke-i

$F_{t}=$ nilai ramalan pada periode ke-i

$n=$ banyaknya periode waktu

\section{HASIL DAN PEMBahasan}

\section{A. Form Login}

Pada halaman login ini berfungsi untuk validasi admin agar dapat mengakses sistem yang dapat dibuat. Berikut ini adalah tampilan halaman login yang dapat dilihat pada Gambar 3.

$$
\text { Login }
$$

$$
\text { odmin }
$$

\section{LOGN}

\section{B. Halaman Admin}

\section{Gambar 3. Halaman Login}

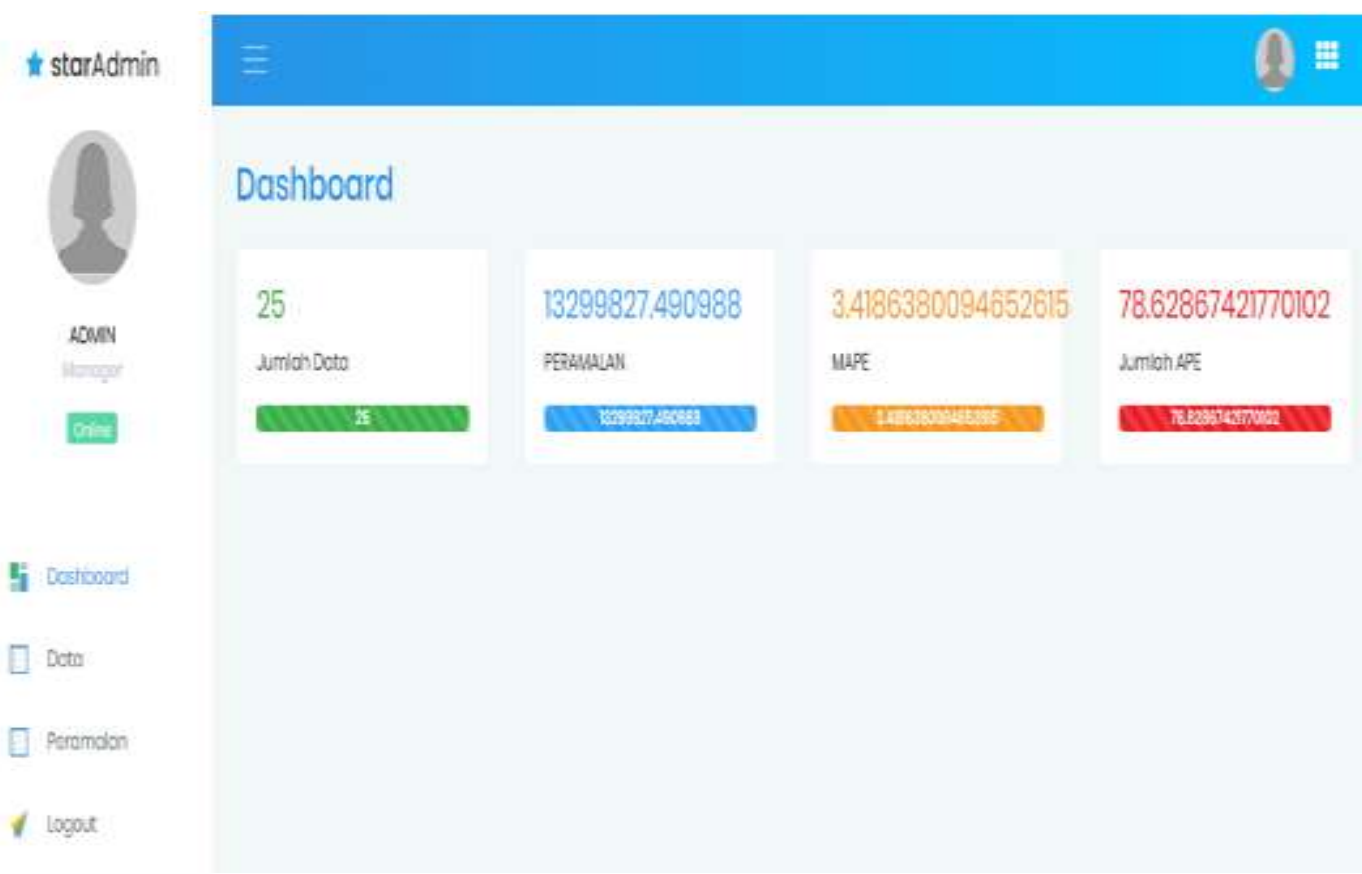

Gambar 4. Halaman Admin

Halaman admin yang bias dilihat pada Gambar 4 ini digunakan untuk menunjukkan jumlah data yang berhasil di input, nilai peramalan, nilai MAPE dan nilai jumlah APE. Halaman admin ini terdapat menu :

1. Menu Data 
Procedia of Engineering and Life Science Vol. 1. No. 2 Juni 2021

Seminar Nasional \& Call Paper Fakultas Sains dan Teknologi (SENASAINS $2^{\text {nd }}$ )

Universitas Muhammadiyah Sidoarjo

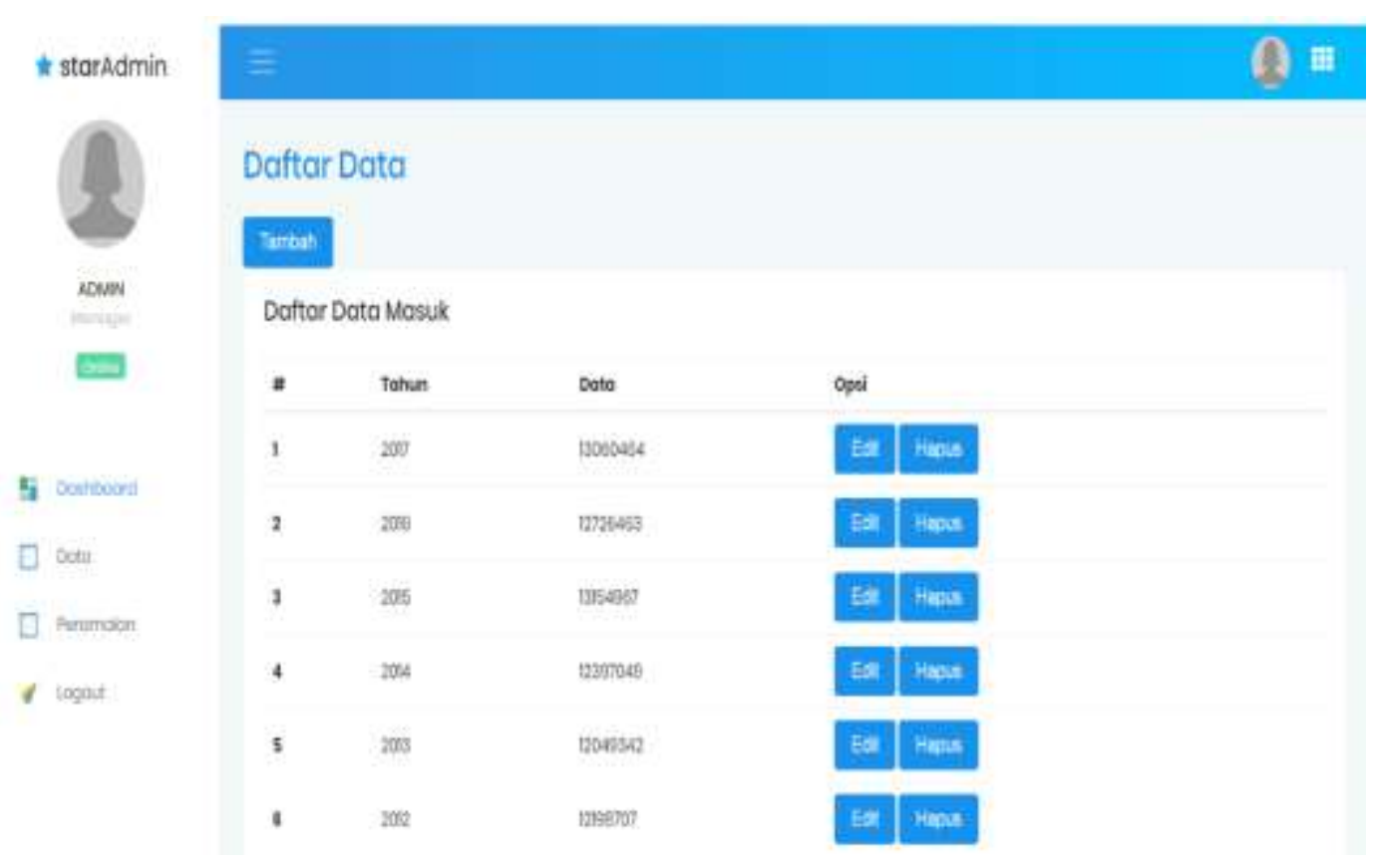

Gambar 5. Tampilan Menu Data.

Pada halaman data produksi ini berfungsi untuk memasukkan data produksi padi yang meliputi periode dan hasil produksi pertahun. Pada halaman ini terdapat tiga button yaitu tambah, edit dan hapus. Button tambah digunakan untuk menambahkan data produksi padi tiap tahunnya, button edit digunakan untuk mengubah data produksi padi bila ada kesalahan dalam menginputkan data. Berikut tampilan halaman penjualan dapat dilihat pada Gambar 5.

2. Menu Peramalan

Tampilan halaman menu peramalan pada gambar 6 ini berfungsi untuk menampilkan peramalan secara singkat. Pada tampilan halaman ini terdapat button ganti nilai yang berfunsi untuk mengganti nilai alpha, dan akan menampilkan hasil peramalan dan mape dari nilai alpha yang dipilih setiap tahunnya. Dibwahnya terdapat pemberitahuan nilai MAPE terkecil, hasil peramalan dari MAPE tersebut.

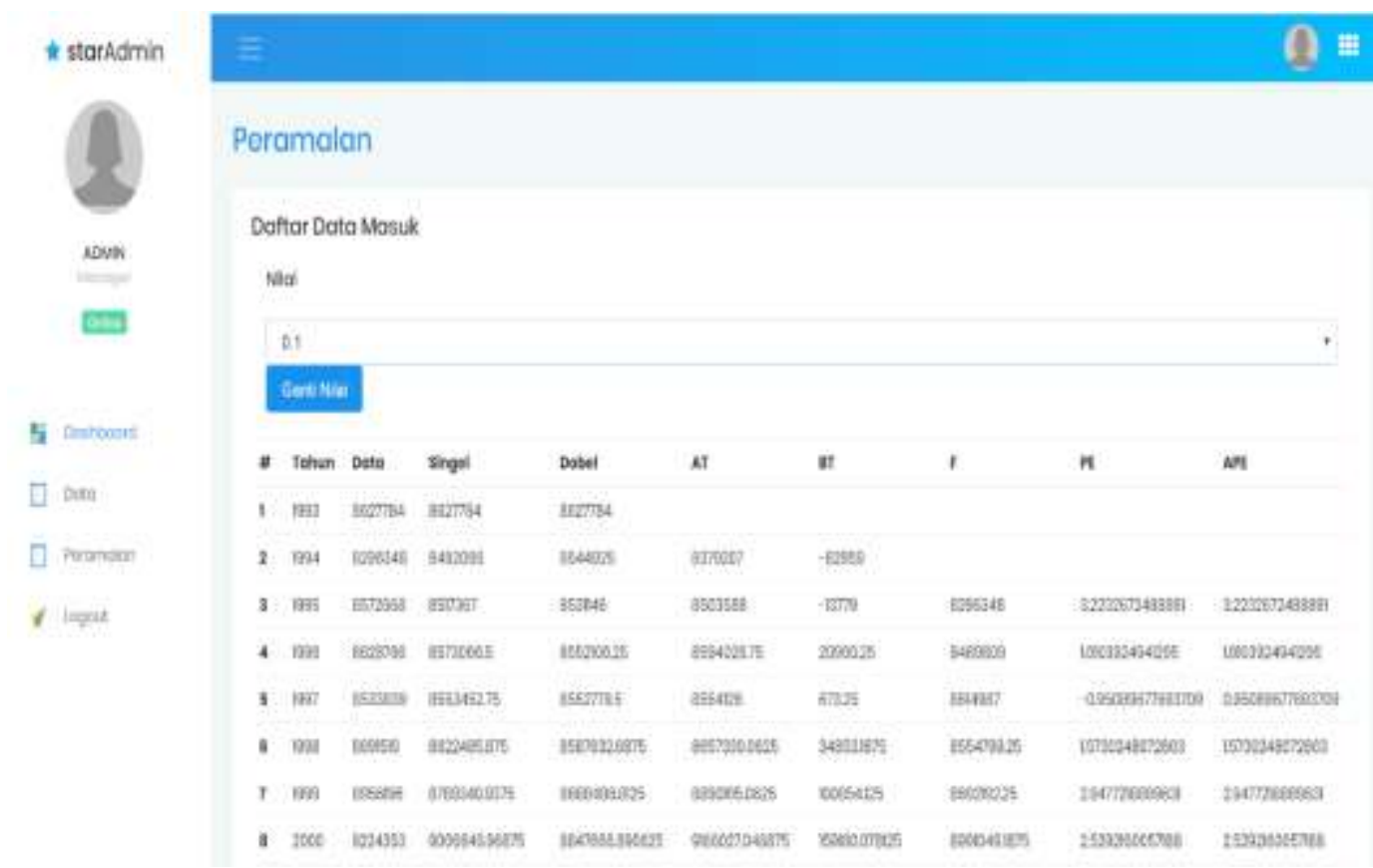

Gambar 6. Tampilan Menu Peramalan

\section{Menu Grafik}

Tampilan menu grafik di 7 menampilkan grafik hasil peramalan dan data real. Pada tampilan halaman ini terdapat button data real berfungsi untuk menampilkan grafik peramalan, dan button peramalan berfungsi untuk menampilkan grafik data real. 
Procedia of Engineering and Life Science Vol. 1. No. 2 Juni 2021

Seminar Nasional \& Call Paper Fakultas Sains dan Teknologi (SENASAINS $2^{\text {nd }}$ )

Universitas Muhammadiyah Sidoarjo

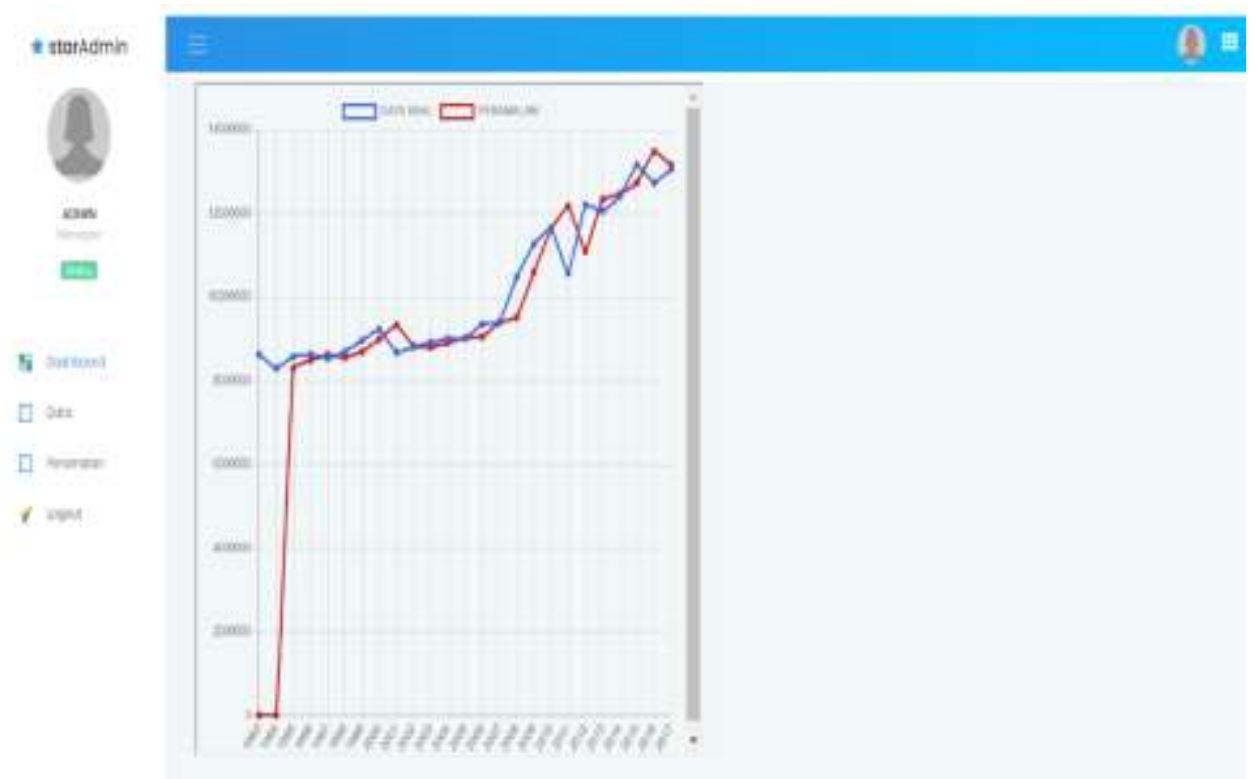

\subsubsection{Hasil Perhitungan}

Gambar 7. Tampilan Menu Grafik.

Untuk hasil perhitungan peramalan terdapat nilai alpha 0,1 sampai 0,9 yang masing-masing menghasilkan nilai yang berbeda. Untuk tampilan hasil nilai alpha 0,1 ditunjukkan pada gambar 8 .

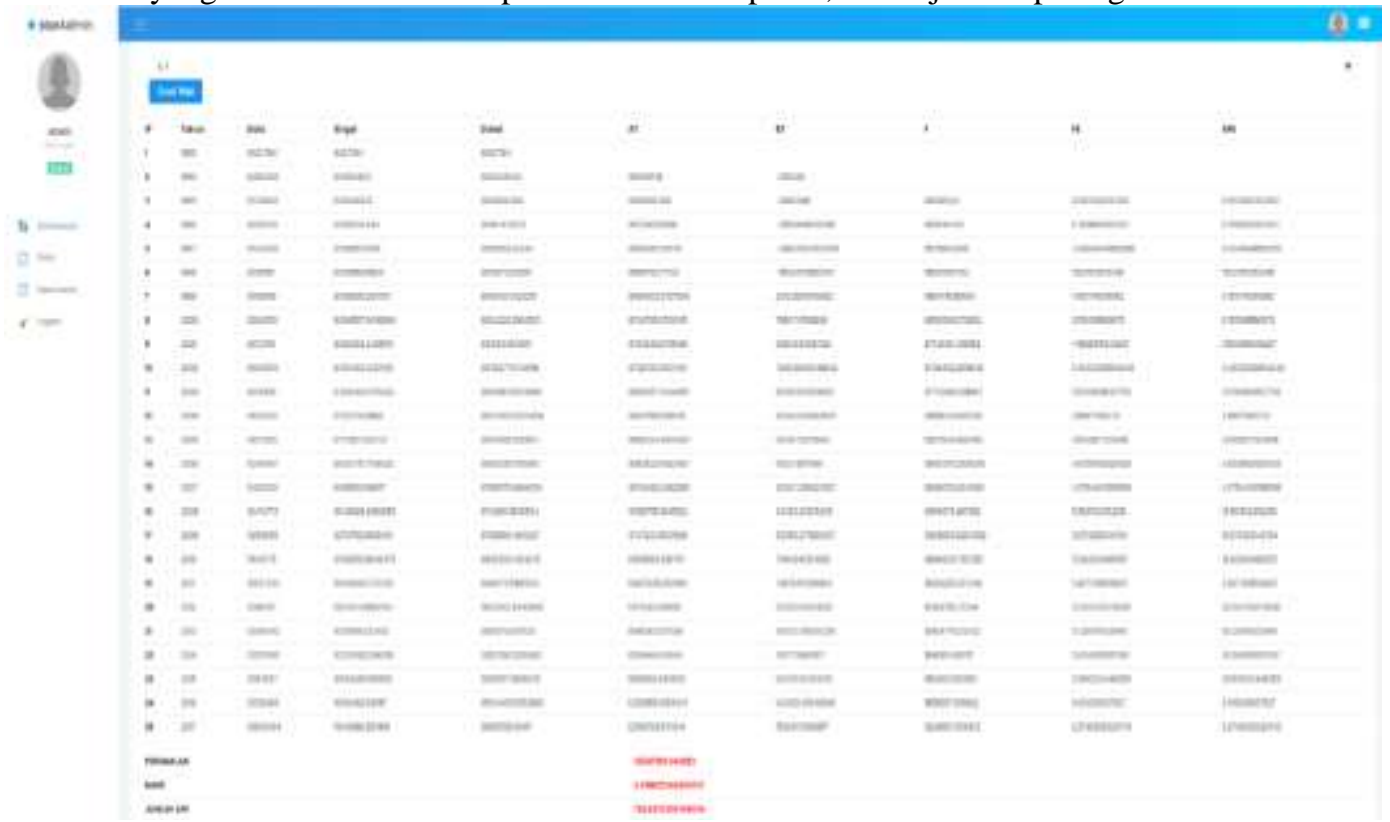

Gambar 8. Hasil perhitungan alpa 0,1

Dari hasil perhitungan alpha 0,1 mendapatkan hasil angka peramalan 12547350,942923, dan terdapat nilai MAPE di bawah hasil peramalan yaitu nilai MAPE 6,019023342454757 dan jumlah nilai APE sebesar 138,4375368764594 . 


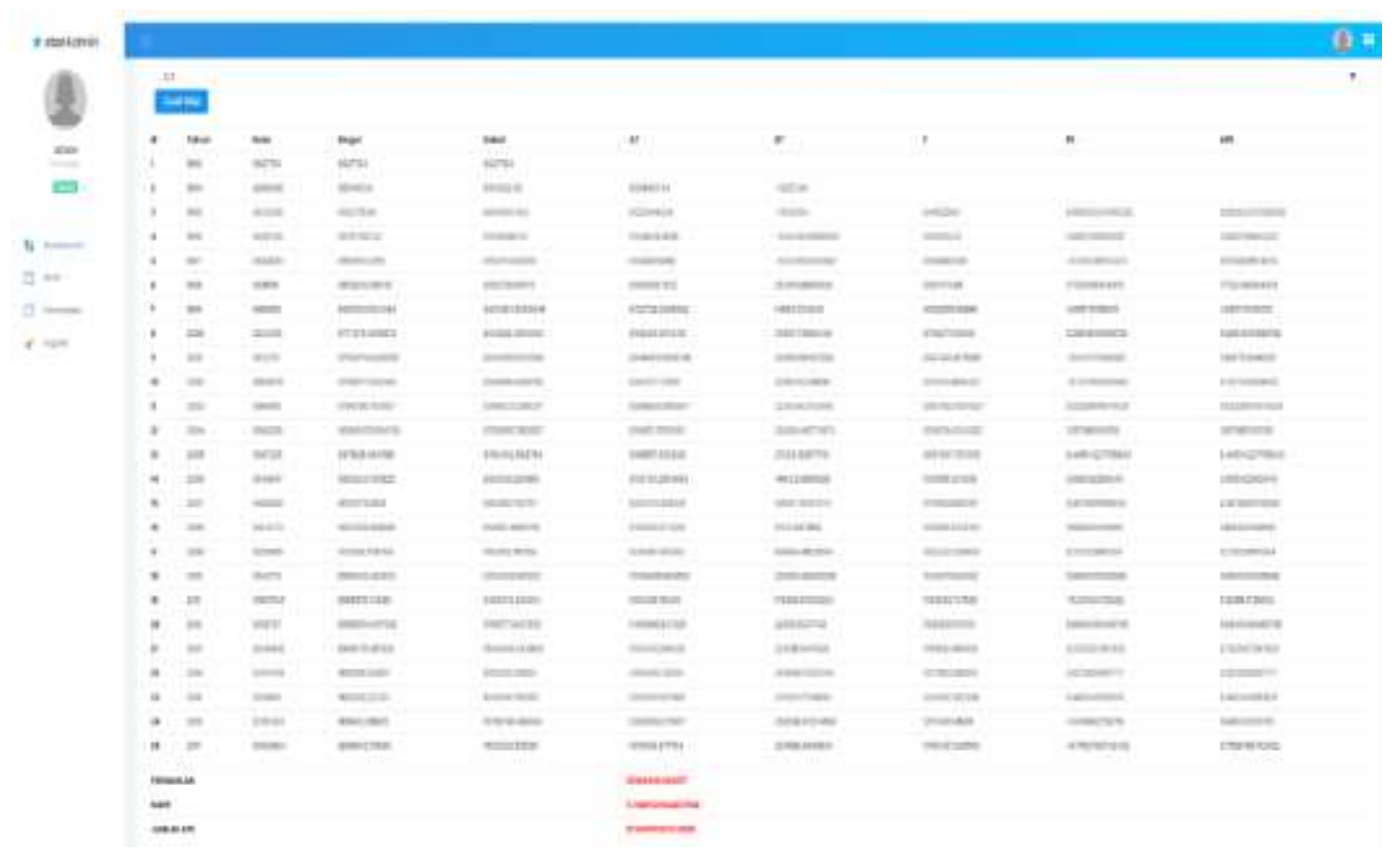

Gambar 9. Hasil Perhitungan alpa 0,2

Dari gambar 9 didapatkan angka peramalan 13384546,920877, angka MAPE 3,7846522641437224 dan jumlah APE sebesar 87,04700207530561. Dan selanjutnya perhitungan yang sama untuk parameter alfa yang lain. Pengujian

Dalam pengujian system peramalan menggunakan metode double exponential smoothing dilakukan dengan cara membandingkan nilai MAPE terkecil dari setiap alfa. Berikut hasil perbandingan MAPE pada alfa 0.1 sampai dengan 0.9 yang ditunjukkan pada Tabel 2.

Tabel 2. Hasil perbandingan MAPE

\begin{tabular}{|c|c|c|}
\hline No & Alfa & MAPE \\
\hline 1 & 0.1 & 6,019023 \\
\hline 2 & 0.2 & 3,784652 \\
\hline 3 & 0.3 & 3,446539 \\
\hline 4 & 0,4 & 3,440229 \\
\hline 5 & 0,5 & 3,418638 \\
\hline 6 & 0,6 & 3,66606 \\
\hline 7 & 0,7 & 4,024783 \\
\hline 8 & 0,8 & 4,409893 \\
\hline 9 & 0,9 & 4,961147 \\
\hline
\end{tabular}

Dari Tabel 2 diketahui bahwa nilai MAPE terkecil didapatkan pada alfa 0.5 yaitu sebesar 3.42. Oleh karena itu didapat keakurasian system sebesar 96.58\%. Dikarenakan MAPE terkecil didapat dari alfa 0.5 menunjukkan bahwa pola data produksi padi tahun 1993-2017 tidak terlalu fluktuatif sehingga pemulusannya mendekati 0. 


\section{KESIMPULAN}

Dari hasil pengujian data produksi padi di provinsi Jawa Timur mulai tahun 1993-2017 didapatkan hasil peramalan untuk periode selanjutnya sebesar 13299827,49098 ton padi. Hasil peramalan ini didapatkan dari parameter alfa 0.5 , dengan didapatkannya hasil peramalan dengan memperhitungkan MAPE terkecil di alfa tersebut, dapat diketahui bahwa data produksi pada tidak begitu fluktuaktif jadi parameter pemulusannya tidak terlalu tinggi.

\section{REFERENSI}

[1] I. Nurhati, S. Ramdhaniati, and N. Zuraida, "Peranan dan Dominasi Varietas Unggul Baru dalam Peningkatan Produksi Padi di Jawa Barat," Bul. Plasma Nutfah, vol. 14, no. 1, p. 8, 2016, doi: 10.21082/blpn.v14n1.2008.p8-13.

[2] H. D. P. Habsari, I. Purnamasari, and D. Yuniarti, "PERAMALAN MENGGUNAKAN METODE DOUBLE EXPONENTIAL SMOOTHING DAN VERIFIKASI HASIL PERAMALAN MENGGUNAKAN GRAFIK PENGENDALI TRACKING SIGNAL ( Studi Kasus : Data IHK Provinsi Kalimantan Timur ) Forecasting Uses Double Exponential Smoothing Method and Forecastin," J. Ilmu Mat. dan Terap., vol. 14, no. 1, pp. 13-22, 2020.

[3] A. Purwanto and S. N. Afiyah, "Sistem Peramalan Produksi Jagung Provinsi Jawa Barat Menggunakan Metode Double Exponential Smoothing," J. Ilm. Teknol. Inf. Asia, vol. 14, no. 2, p. 85, 2020, doi: 10.32815/jitika.v14i2.462.

[4] S. N. Afiyah and D. K. Wijaya, "Sistem Peramalan Indeks Harga Konsumen (IHK) Menggunakan Metode Double Exponential smoothing," J. Ilm. Teknol. Inf. Asia, vol. 12, no. 1, p. 56, 2018, doi: 10.32815/jitika.v12i1.243.

[5] R. Fajri and T. M. Johan, "Implementasi Peramalan Double Exponential Smoothing Pada Kasus Kekerasan Anak Di Pusat Pelayanan Terpadu Pemberdayaan Perempuan Dan Anak," J. ECOTIPE, vol. 4, no. 2, pp. 613, 2017, doi: 10.33019/ecotipe.v4i2.6.

[6] E. Pujiati, D. Yuniarti, and R. Goejantoro, "Peramalan Dengan Menggunakan Metode Double Exponential Smoothing Dari Brown (Studi Kasus : Indeks Harga Konsumen (IHK) Kota Samarinda), J.

EKSPONENSIAL, vol. 7, no. 1, pp. 33-40, 2016, [Online]. Available:

http://jurnal.fmipa.unmul.ac.id/index.php/exponensial/article/view/23.

[7] W. Sari, "Perbandingan Metode Double Exponential Smoothing, Simple Moving Average dan Least Square untuk Forecasting Penjualan Semen,” pp. 1-83, 2020.

[8] S. Marlianah, C. Meilani, Q. Lina, and E. Widodo, “Analisis Double Exponential Smoothing Untuk Meramalkan Utang Pemerintah Indonesia ke Luar Negeri ( Studi Kasus : Data Utang Pemerintah Indonesia ke Luar Negeri dari Bulan Januari 2010 sampai April 2019 ),” Semin. Nas. MIPA UNIBA, no. April, pp. 184-191, 2019.

[9] F. I. Y. Dwi Hilda Anjasari, Eko Listiwikono, "Perbandingan Metode Double Exponential Smoothing Holt Dan Metode Triple Exponential Smoothing Holt-Winters Untuk Peramalan Wisatawan Grand Watu Dodol PERBANDINGAN," J. Pendidik. Mat. Mat., vol. 2, no. 2, pp. 12-25, 2018.

[10] R. Ariyanto, D. Puspitasari, and F. Ericawati, "Penerapan Metode Double Exponential Smoothing Pada Peramalan Produksi Tanaman Pangan,” J. Inform. Polinema, vol. 4, no. 1, p. 57, 2017, doi: 10.33795/jip.v4i1.145.

[11] I. Sungkawa and R. T. Megasari, "NILAI RAMALAN DATA DERET WAKTU DALAM SELEKSI MODEL PERAMALAN VOLUME PENJUALAN PT SATRIAMANDIRI CITRAMULIA Iwa Sungkawa; Ries Tri Megasari," ComTech, vol. 2, no. 2, pp. 636-645, 2011. 